\title{
Neurofibromin Regulates Neural Stem Cell Proliferation, Survival, and Astroglial Differentiation In Vitro and In Vivo
}

\author{
Biplab Dasgupta and David H. Gutmann \\ Department of Neurology, Washington University School of Medicine, St. Louis, Missouri 63110
}

\begin{abstract}
Neurofibromatosis 1 (NF1) is a common inherited disease in which affected children exhibit abnormalities in astrocyte growth regulation and are prone to the development of brain tumors (astrocytoma). Previous studies from our laboratory demonstrated that Nf1 mutant mouse astrocytomas contains populations of proliferating nestin + progenitor cells, suggesting that immature astroglial progenitors may serve as a reservoir of proliferating tumor cells. Here, we directly examined the consequences of $N f 1$ inactivation on neural stem cell (NSC) proliferation in vitro and in vivo. We found dose-dependent effects of neurofibromin expression on NSC proliferation and survival in vitro, which reflected increased RAS pathway activation and increased bcl 2 expression. In addition, unlike wild-type NSCs, Nf1-INSCs and, to a lesser extent, $N f 1+/-$ NSCs survive as xenografts in naive recipient brains in vivo. Although Nf1-I- NSCs are multipotent, $\mathrm{Nf1}-\mathrm{I}-$ and $\mathrm{Nf1}+/-$, but not wild-type, NSCs generated increased numbers of morphologically abnormal, immature astroglial cells in vitro. Moreover, the NfI-I- NSC growth and survival advantage as well as the astroglial cell differentiation defect were completely rescued by expression of the GAP (RAS-GTPase activating protein) domain of neurofibromin. Finally, the increase in astroglial progenitors and proliferating cells seen in vitro was also observed in $\mathrm{NfI-I}$ - and $\mathrm{NfI}+/-$ embryonic as well as $\mathrm{NfI}+/$ - adult brains in vivo. Collectively, these findings support the hypothesis that alterations in neurofibromin expression in the developing brain have significant consequences for astrocyte growth and differentiation relevant to normal brain development and astrocytoma formation in children.
\end{abstract}

Key words: GTPase activating protein; RAS; neurosphere; stem cell; glia; neurofibromatosis 1

\section{Introduction}

Neurofibromatosis 1 (NF1) is a common genetic condition affecting the nervous system. Although the hallmark of the disease is the development of peripheral nervous system tumors (neurofibromas), the CNS is frequently involved (Gutmann et al., 1997). In this regard, 15-20\% of children develop low-grade glial cell neoplasms (World Health Organization grade I pilocytic astrocytomas), typically located within the optic pathway (Listernick et al., 1994, 1999), termed optic pathway glioma (OPG).

In mice, reduced or absent $N f 1$ gene expression confers a proliferative advantage to astrocytes in vitro and in vivo (Bajenaru et al., 2001, 2002). In this regard, $N f 1+/-$ mice with astrocyte $N f 1$ inactivation develop OPGs (Bajenaru et al., 2003). Consistent with the established function of the NF1 gene product (neurofibromin) in RAS inhibition (Ballester et al., 1990; Martin et al., 1990; Xu et al., 1990), OPGs also arise in $\mathrm{Nf1}+/-$ mice as a result of dysregulated K-RAS activity in astrocytes (Dasgupta et al., 2005).

The availability of mouse models of NF1-associated glioma

Received Nov. 16, 2004; revised April 4, 2005; accepted May 1, 2005.

This work was supported by a grant from the United States Army (DAMD-17-03-1-0215 to D.H.G.). We thank Katherine Gold for advice with neurosphere generation, Christine Kamp for technical assistance, and Dr. Jason Weber for the MSCV-GFP viral construct.

Correspondence should be addressed to Dr. David H. Gutmann, Department of Neurology, Washington University School of Medicine, Box 8111, 660 South Euclid Avenue, St. Louis, M0 63110. E-mail: gutmannd@neuro.wustl.edu. DOI:10.1523/JNEUROSCI.4693-04.2005

Copyright $\odot 2005$ Society for Neuroscience $\quad$ 0270-6474/05/255584-11\$15.00/0 provides a unique opportunity to study the molecular and cellular pathogenesis of these brain tumors. To this end, examination of OPG arising in these genetically engineered $N f 1$ mutant mice has revealed the presence of nests of proliferating nestin- and brain lipid-binding protein- (BLBP) immunoreactive cells within the evolving tumor (Bajenaru et al., 2005). The identification of cells expressing markers associated with neural stem/progenitor cells in these mouse brain tumors (Lendahl et al., 1990; Malatesta et al., 2000; Noctor et al., 2000; Hartfuss et al., 2001) raises the intriguing possibility that gliomas in children with NF1 might develop from proliferating NF1-/- progenitor cells.

In keeping with this notion, recent studies have identified a small fraction of highly proliferating cells within tumors that express markers of stem/progenitor cells. These "cancer stem cells" have been observed in a wide variety of diverse human cancers, including myeloid leukemia (Hope et al., 2004), breast cancer (Al-Hajj et al., 2003), and high-grade glioma (Hemmati et al., 2003; Singh et al., 2003; Galli et al., 2004). Moreover, cancer stem cells have also been isolated from pediatric brain tumors, including pilocytic astrocytoma (Singh et al., 2003), suggesting that aberrantly proliferating stem/progenitor cells might be involved in the formation of NF1-associated OPG.

Given both the clinical brain manifestations of NF1 and several lines of converging evidence that loss of neurofibromin in CNS cells may impair astroglial cell proliferation (Bajenaru et al., 2002; Bennett et al., 2003), we directly examined the consequence of neurofibromin loss on neural stem cell (NSC) proliferation in 
vitro and in vivo. We demonstrate that $N f 1$ inactivation profoundly affects NSC proliferation and survival as well as astroglial cell differentiation and that these functions of neurofibromin are mediated by residues within the NF1-RASGAP (RAS-GTPase activating protein) domain (GRD). Importantly, we show that $N f 1$ heterozygosity, as seen in NF1 patient brains, results in defective cell proliferation in vitro and the persistence of aberrantly proliferating and differentiating cells in the developing and adult brain in vivo.

\section{Materials and Methods}

Mice. $N f 1+/-$ mice (a generous gift from Dr. Neal Copeland, National Institutes of Health, Bethesda, MD) (Brannan et al., 1994) were mated to generate embryos of each genotype. These mice were maintained as permanent colonies in the Department of Comparative Medicine small animal barrier facility at Washington University School of Medicine in accordance with approved Animal Studies Committee protocols.

Isolation and culture of neurospheres. CNS telencephalic lobes were removed from embryonic day 10.5 (E10.5) decidua of time-pregnant females and processed to obtain single-cell suspension of neural progenitors (neurospheres) as described previously (Molofsky et al., 2003), with minor modifications. Vesicles were digested with trypsin digest buffer containing $0.2 \%$ BSA (Sigma, St. Louis, MO), $0.5 \mathrm{mg} / \mathrm{ml}$ DNase I (Sigma), and $10 \%$ trypsin-EDTA stock (BioWhittaker, Walkersville, $\mathrm{MD}$ ) in $\mathrm{HBSS}$ at $37^{\circ} \mathrm{C}$ for $10 \mathrm{~min}$ in a volume of $0.7 \mathrm{ml}$ per vesicle. Equal volumes of 10\% FCS medium containing 10\% FCS (Life Technologies, Gaithersburg, MD), $2 \mathrm{~mm}$ L-glutamine (BioWhittaker), $0.1 \%$ glucose (Sigma), and $0.1 \mathrm{~mm}$ 2-mercaptoethanol (Sigma) in DMEM/F-12 (Sigma) were added, and vesicles were triturated with fire-polished Pasteur pipettes. Pelleted cells were washed with dissociation medium containing $0.1 \%$ sodium bicarbonate, $15 \mathrm{~mm}$ HEPES (Sigma), $0.5 \%$ glucose, and $0.2 \%$ BSA in HBSS. Cells were finally resuspended either in defined medium (Tropepe et al., 1999; Arsenijevic et al., 2001) or in NSC medium containing a 5:3 mixture of DMEM low glucose:Neurobasal medium (Life Technologies), $0.5 \mathrm{~mm}$ 2-mercaptoethanol, $2 \mathrm{~mm}$ L-glutamine, 5 IU of penicillin, and $5 \mu \mathrm{g} / \mathrm{ml}$ streptomycin (BioWhittaker) supplemented with $1 \% \mathrm{~N} 2$ supplement (Life Technologies), 2\% B27 supplement (Life Technologies), $20 \mathrm{ng} / \mathrm{ml}$ epidermal growth factor (EGF) (Sigma), and $20 \mathrm{ng} / \mathrm{ml}$ basic fibroblast growth factor (FGF) (R \& D Systems, Minneapolis, MN).

Measurements of in vitro cell proliferation and self-renewal. Ultra-low binding plates (Corning, Corning, NY) were used for all suspension cultures, proliferation, and self-renewal experiments. To assess proliferation, $10^{4}$ cells of each genotype were seeded in triplicate. At each time point, resulting neurospheres were trypsinized and counted on a hemocytometer. For self-renewal assays, 10 single neurospheres of each genotype were triturated before plating, and the number of resulting neurospheres generated was counted after $7 \mathrm{~d}$. For the clonogenic incidence experiments (Nunes et al., 2003), we used retroviral green fluorescent protein (MSCV-GFP) to generate GFP-labeled cells and seeded 2000 $\mathrm{GFP}+$ cells from the fourth passage. The clonogenic incidence was calculated as the number of neurospheres formed $(\times 100)$ divided by the number of NSCs originally seeded. The number of resulting neurospheres generated after $7 \mathrm{~d}$ were counted.

For limiting dilution analysis (Tropepe et al., 1999), 5-1000 cells were seeded in five wells per dilution for each genotype, and the percentage of wells with at least one neurosphere was calculated. One hundred neurospheres were selected randomly, and their diameters were calculated using Analysis Imager software (Soft Imaging System, Lakewood, CO). For ectopic expression of NF1GRD, we used a retrovirus containing a KT3tagged NF1 GAP (RAS-GTPase activating protein)-related domain (NF1GRD or NF1GRD containing the R1276P NF1 patient mutation) transgene (MSCV-NF1GRD or MSCV-NF1GRD-R1276P) and a puromycin resistance gene $(\mathrm{Pac})$. Cells were infected with either MSCVNF1GRD or MSCV-Pac (control), and puromycin-resistant cells were selected after $3 \mathrm{~d}$. To determine the role of the cAMP, mitogen-activated protein (MAP) kinase, and phosphatidylinositol 3'-kinase (PI3K)-Akt pathways in NSC proliferation, self-renewal, survival, and differentiation, we used the cAMP analog dibutyril-cAMP $(100 \mu \mathrm{M}$ and $200 \mu \mathrm{M})$, the MAP kinase (MAPK) kinase (MEK kinase) inhibitor 2-(2-Amino-3methoxyphenyl)-4H-1-benzopyran-4-one (PD98059; $20 \mu \mathrm{M}$ ), and the PI3K inhibitor 2-(4-Morpholinyl)-8-phenyl-1(4H-benzopyran-4-one hydrochloride (LY294002; 10 and $20 \mu \mathrm{M}$ ).

In vitro cell survival and death. Nf1+/+ and Nf1-/- NSCs were grown in defined medium containing $1.2 \mathrm{mg} / \mathrm{ml}$ sodium bicarbonate, 5 $\mathrm{ng} / \mathrm{ml}$ insulin (Sigma), $0.1 \mathrm{mg} / \mathrm{ml}$ apotransferrin (Life Technologies), 5 $\mathrm{ng} / \mathrm{ml}$ sodium selenite (Sigma), $6 \mathrm{ng} / \mathrm{ml}$ progesterone (Sigma), $0.25 \%$ glucose, $6 \mu \mathrm{g} / \mathrm{ml}$ putrescine (Sigma), $2 \mathrm{~mm}$ L-glutamine, and $0.1 \mathrm{~mm}$ 2-mercaptoethanol (Tropepe et al., 1999; Arsenijevic et al., 2001; Engstrom et al., 2002). This medium did not contain N2 and B27 supplement, EGF, or FGF. After $72 \mathrm{~h}$ of growth-factor deprivation and $1 \mathrm{~h}$ of 10 $\mu \mathrm{M}$ bromodeoxyuridine (BrdU; Sigma) exposure, cells were allowed to attach to poly-D-lysine-coated plates (Ciccolini and Svendsen, 1998). Cells were fixed in $100 \%$ methanol for $10 \mathrm{~min}$ at $4^{\circ} \mathrm{C}$. DNA denaturation was accomplished using $2 \mathrm{~N} \mathrm{HCl}$ for $30 \mathrm{~min}$ at room temperature, followed by neutralization with two changes of $0.1 \mathrm{M}$ sodium borate buffer, $\mathrm{pH}$ 8.5, for 10 min (Molofsky et al., 2003). Apoptotic and proliferating cells were detected using antibodies to cleaved caspase-3 (Cell Signaling Technology, Beverly, MA) and BrdU (Abcam, Cambridge, MA), respectively.

NSC differentiation. Individual neurospheres were selected and seeded individually onto poly-D-lysine (50 $\mu \mathrm{g} / \mathrm{ml})$-coated and fibronectin (10 $\mu \mathrm{g} / \mathrm{ml}$; Life Technologies)-coated wells and allowed to differentiate in growth factor-free N2, B27 supplemented medium (Tropepe et al., 1999). Cells were stained with rabbit anti-GFAP (Abcam), mouse antiTuj1 (Covance, Berkeley, CA), and mouse anti-O4 IgM (Chemicon, Temecula, CA) primary antibodies, followed by incubation with appropriate Alexa Fluor-tagged secondary antibodies (Molecular Probes, Eugene, OR) to detect astrocytes, neurons, and oligodendrocytes, respectively. Additional immunocytochemistry also used rabbit anti-BLBP (a gift from Dr. Jeffrey E. DeClue, National Cancer Institute, Bethesda MD), mouse anti-vimentin (Sigma), mouse anti-RC2 IgM (Developmental Studies Hybridoma Bank, Department of Biological Studies, The University of Iowa, Iowa City, IA), and mouse anti-CD44 (Chemicon) antibodies. Undifferentiated neurospheres were characterized using mouse anti-nestin (Chemicon) and rat anti-CD133 (R \& D Systems) antibodies.

Western blot analysis. Western blots were performed as described previously (Dasgupta et al., 2003). Active RAS (RAS-GTP) was detected by Rafl-RBD affinity chromatography using the RAS activation assay kit (Upstate Biotechnology, Lake Placid, NY) according to the manufacturer's recommendations (Dasgupta et al., 2005). The primary antibodies used were as follows: rabbit anti-NF1GRP-D (Santa Cruz Biotechnology, Santa Cruz, CA); mouse anti-KT3 (Covance, Richmond, CA); mouse anti-Bcl2 (BD Transduction Laboratories, Lexington KY); mouse antiphospho-MAPK $\left(\mathrm{Thr}^{202} / \mathrm{Tyr}^{204}\right)$, mouse anti-phospho-Akt $\left(\mathrm{Ser}^{473}\right)$, rabbit anti-MAPK, and rabbit anti-Akt (all from Cell Signaling Technology); and mouse anti- $\alpha$-tubulin (Sigma). Appropriate HRP-tagged secondary antibodies (Cell Signaling Technology) were used for detection by enhanced chemiluminescence (Amersham Biosciences, Piscataway, NJ).

5-(and-6)-Carboxyfluorescein diacetate, succinimidyl ester washout experiment. 5-(and-6)-Carboxyfluorescein diacetate, succinimidyl ester (CFSE; Molecular Probes) is a cell-permeable fluorescent dye that is metabolized by nonspecific esterases to result in a compound that gets trapped in the cytosol. Dividing daughter cells receive one-half the amount of dye and, with continued division, lose one-half of the fluorescence with each subsequent cell division. We pulse-labeled both $\mathrm{Nf1}+/+$ and Nf1-/- NSCs with $5 \mu \mathrm{M} \mathrm{CFSE}$ at $37^{\circ} \mathrm{C}$ for $15 \mathrm{~min}$ in the dark. Cells were washed, and one-half of the cells were analyzed by flow cytometry. The remaining cells were allowed to grow for $5 \mathrm{~d}$, and the fluorescence intensity was measured as above (Groszer et al., 2001).

Implantation of NSCs into nu/nu athymic mouse brains. NSCs for implantation were grown for $5-7 \mathrm{~d}$ as neurospheres in vitro as described above. During this time, neurospheres were labeled by adenoviral infection using Ad5LacZ [adenovirus expressing the $\beta$-galactosidase transgene (Yoon et al., 1996)]. Before injection, neurospheres were mildly trypsinized into single cells and smaller spheres and suspended in PBS. Six- to 8-week-old male mice (three to four mice per genotype per time point) were anesthetized with ketamine ( $60 \mu \mathrm{g} / \mathrm{g}$ body weight) and xyla- 
zine $(7.5 \mu \mathrm{g} / \mathrm{g}$ body weight $)$ and placed in a stereotactic frame. A total of $\sim 10^{5}$ cells in a volume of $10 \mu \mathrm{l}$ were injected with a Hamilton Microliter \#170 syringe (Hamilton, Reno, NV), through a bore drilled $2 \mathrm{~mm}$ posterior, $2 \mathrm{~mm}$ lateral from bregma and $3 \mathrm{~mm}$ below the brain surface. The scalp was closed with a stapler clip, and the mice were allowed to recover.

In vivo BrdU labeling, tissue preparation, and immunohistological anal$y$ sis. For in vivo cell proliferation experiments, adult $\mathrm{Nf1}+\mathrm{I}+$ and $\mathrm{Nf1}+/$ - mice were given injections of BrdU ( $50 \mu \mathrm{g} / \mathrm{g}$ body weight). One hour after injection, anesthetized animals were perfused transcardially with $0.1 \mathrm{~m}$ sodium phosphate buffer, $\mathrm{pH} 7.4$, followed by $4 \%$ paraformaldehyde in $0.1 \mathrm{M}$ sodium phosphate buffer. To detect the $\beta$-galactosidase activity of injected NSCs, mice were perfused similarly. For in vivo progenitor cell analysis, time-pregnant females were killed at E12.5, and $\mathrm{Nf1}+/+, \mathrm{Nf1}+/-$, and $\mathrm{Nf1}-/$ - embryos were collected. The brains of adult animals and entire embryos were fixed overnight with $4 \%$ paraformaldehyde at $4^{\circ} \mathrm{C}$, cryoprotected in $30 \%$ sucrose in $0.1 \mathrm{~m}$ phosphate buffer at $4^{\circ} \mathrm{C}$, embedded in OCT compound, and frozen in cryomolds in liquid nitrogen. Cryosections were collected on Superfrost glass slides. LacZ expression was detected by incubating the sections with 5-bromo4-chloro-3-indolyl- $\beta$-D-galactopyranoside (X-gal) staining solution (Bajenaru et al., 2002).

For the BrdU incorporation experiments, frozen sections were postfixed in $100 \%$ methanol for $10 \mathrm{~min}$ at $4^{\circ} \mathrm{C}$. DNA denaturation was accomplished using $2 \mathrm{~N} \mathrm{HCl}$ for $30 \mathrm{~min}$ at room temperature, followed by neutralization with two changes of $0.1 \mathrm{~m}$ sodium borate buffer, $\mathrm{pH} 8.5$, for $10 \mathrm{~min}$ (Molofsky et al., 2003). All other sections were postfixed in 4\% paraformaldehyde. The brains 4 and 6 months post-injection (p.i.) were fixed with Bouin's fixative and processed for paraffin embedding and sectioning $(4 \mu \mathrm{m})$ in the Pharmacology Histology Core at Washington University School of Medicine. Sections were stained with hematoxylin and eosin (H\&E) or used for immunohistochemistry using the microwave antigen-retrieval method (Bajenaru et al., 2003).

The following primary antibodies were used for in vivo immunohistochemical analysis: GFAP (Abcam); BLBP (a gift from Dr. Nathaniel Heintz, The Rockefeller University, New York, NY); Sox2, Olig1, and Nkx2.2 (all from Chemicon); Tuj1 (Covance, Berkeley CA); doublecortin (Chemicon); CD44 (Chemicon); MAP2 (Sigma); BrdU (Abcam); and Ki67 (Novocastra, Newcastle, UK). Appropriate Alexa Fluor-tagged secondary antibodies (all from Molecular Probes) were used for detection by immunofluorescence. For paraffin-embedded sections, detection was performed using the Vectastain Elite ABC kit (Vector Laboratories, Burlingame, CA) for GFAP expression, the TSA-Plus fluorescein kit (PerkinElmer, Boston, MA) for BLBP expression, and the VIP substrate kit (Vector Laboratories) for Ki67 immunostaining. All sections were photographed with a digital camera (Optronics, Goleta, CA) attached to an inverted microscope (Nikon, Melville, NY).

Statistical analysis. Student's $t$ test was used to calculate statistical significance with $p<0.05$ representing a statistically significant difference.

\section{Results \\ Neurofibromin negatively regulates proliferation and self- renewal of NSCs in vitro}

Previous studies have shown that neurofibromin loss in embryonic or postnatal astroglial cells results in modest increases in astrocyte proliferation (Bajenaru et al., 2002). To determine the role of the $\mathrm{Nf1}$ gene in astroglial progenitor cell growth control, we used an in vitro NSC culture system. In contrast to $\mathrm{Nfl}-\mathrm{I}-$ astroglial cells from either E12.5 or postnatal day 1 (P1) mice, which exhibit a twofold to threefold increase in proliferation (Bajenaru et al., 2002), Nf1-/ - NSCs proliferated at a significantly higher rate at every time point studied. At $96 \mathrm{~h}$, we observed a 12 -fold increase in the number of Nf1-I- NSCs compared with $\mathrm{Nfl}+/+$ NSCs (Fig. 1a).

To determine the consequence of neurofibromin loss on NSC self-renewal, we counted the number of secondary neurospheres generated by single primary neurospheres. Whereas only $2.25 \%$ of cells of wild-type neurospheres produced secondary neuro-
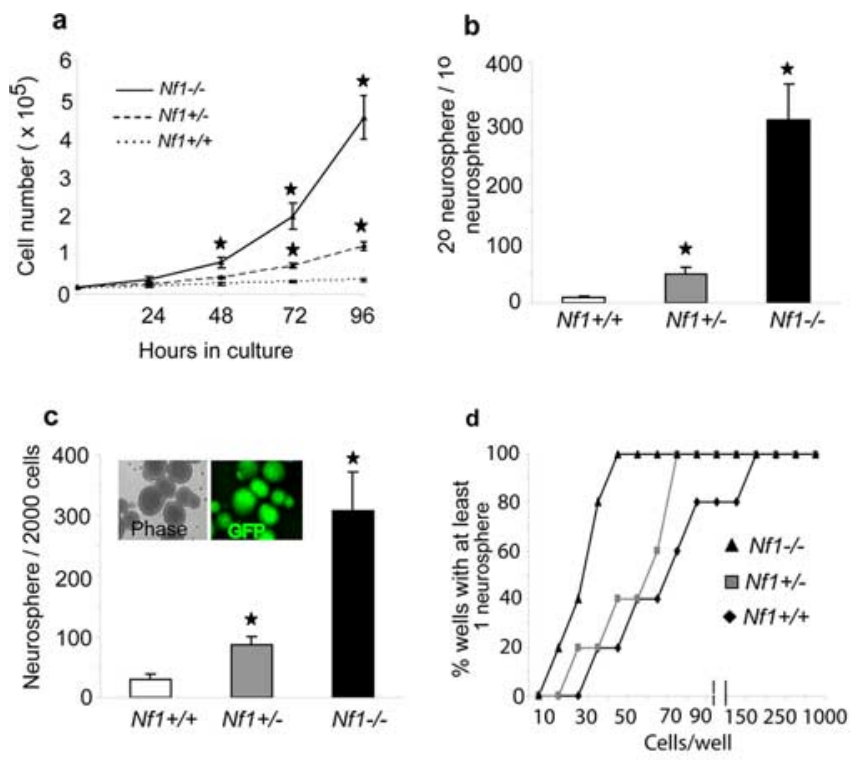

e

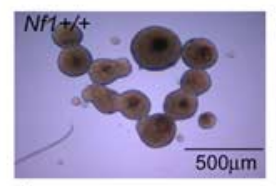

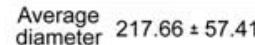

Cells/sphere $385 \pm 44.72$

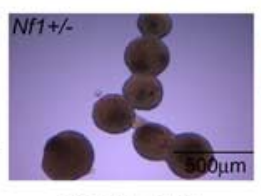

$294.19 \pm 50.82$

$760 \div 58.28$

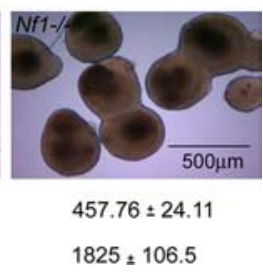

$1825 \div 106.5$

Figure 1. Nf1 loss leads to increased proliferation and self-renewal of NSCs in vitro. $\boldsymbol{a}, \mathrm{In}$ creased numbers of Nf1 $-/-$ NSCs were observed at each time point $(p<0.001)$ compared with $N f 1+/-$ and $N f 1+/+N S C s . \boldsymbol{b}$, The number of secondary neurospheres generated per primary neurosphere (a measure of self-renewal potential) was considerably higher in Nf1 - / - neurospheres $(p<0.001)$. c, Neurospheres of all three genotypes showed clonal origin at low-density culture, with a significantly higher clonogenic incidence of Nf1-Ineurospheres $(p<0.001)$. The inset shows these clonal GFP + neurospheres. $\boldsymbol{d}$, The frequency of NSCs required to form neurospheres (limiting dilution analysis) revealed a much higher frequency of neurosphere formation by Nf1 - I- NSCS., , Nf1 - I- neurospheres were significantly larger $(p<0.005)$ and contained five times more cells per sphere than $\mathrm{Nf1+/+}$ spheres.

spheres, $16.2 \%$ of cells of $\mathrm{Nf1-/-}$ neurospheres generated secondary neurospheres (Fig. 1b). In addition, we found that Nf1-I- NSCs had a clonogenic incidence of $15.37 \%$, compared with $1.52 \%$ for $N f 1+/+$ and $4.36 \%$ for Nf1 $+/$ - NSCs, suggesting a high capacity for secondary neurosphere generation (Fig. 1c).

To determine whether neurospheres formed by $\mathrm{Nf1}-\mathrm{I}-$ NSCs develop as a result of clonal expansion versus cell aggregation, we labeled single NSCs with retroviral GFP. The resulting neurospheres were composed entirely of either GFP+ or GFPcells, suggesting a clonal origin of $N f 1-/-$ neurospheres. Finally, we used limiting dilution analysis to determine the minimal number of cells required to form a neurosphere. Compared with $\mathrm{Nf1}+/+\mathrm{NSCs}$, which required $20 \pm 7.5$ cells to form at least one sphere per well, the minimal number of Nf1-/ - NSCs required to form at least one neurosphere per well was $5 \pm 2.5$. Although $10 \%$ of all wells seeded with $10 \mathrm{Nf1-/}$ - NSCs contained at least one neurosphere, we did not find any wells containing neurospheres using either $\mathrm{Nf1+/}$ or $\mathrm{Nf1}+/-\mathrm{NSCs}$ at this cell dilution (Fig. 1d).

In addition, as the Nf1-/- NSCs were allowed to propagate, the average diameter of their derivative neurospheres and the number of individual cells per sphere were significantly greater than that observed with wild-type NSCs (Fig. 1e). Together, these 
a
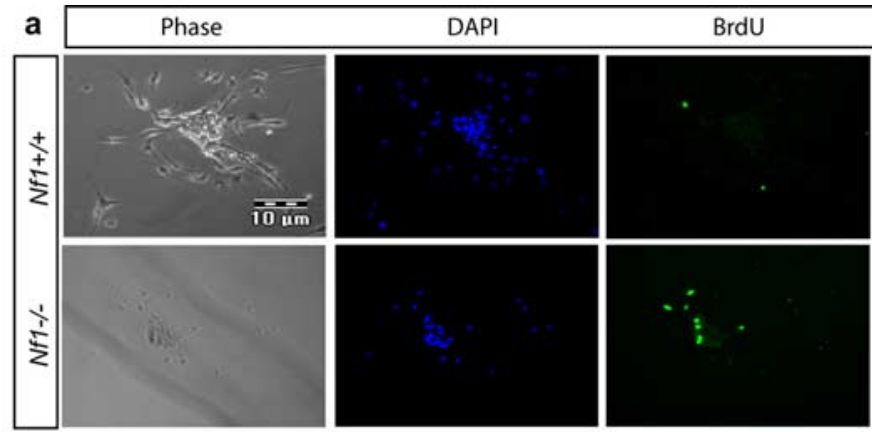

b
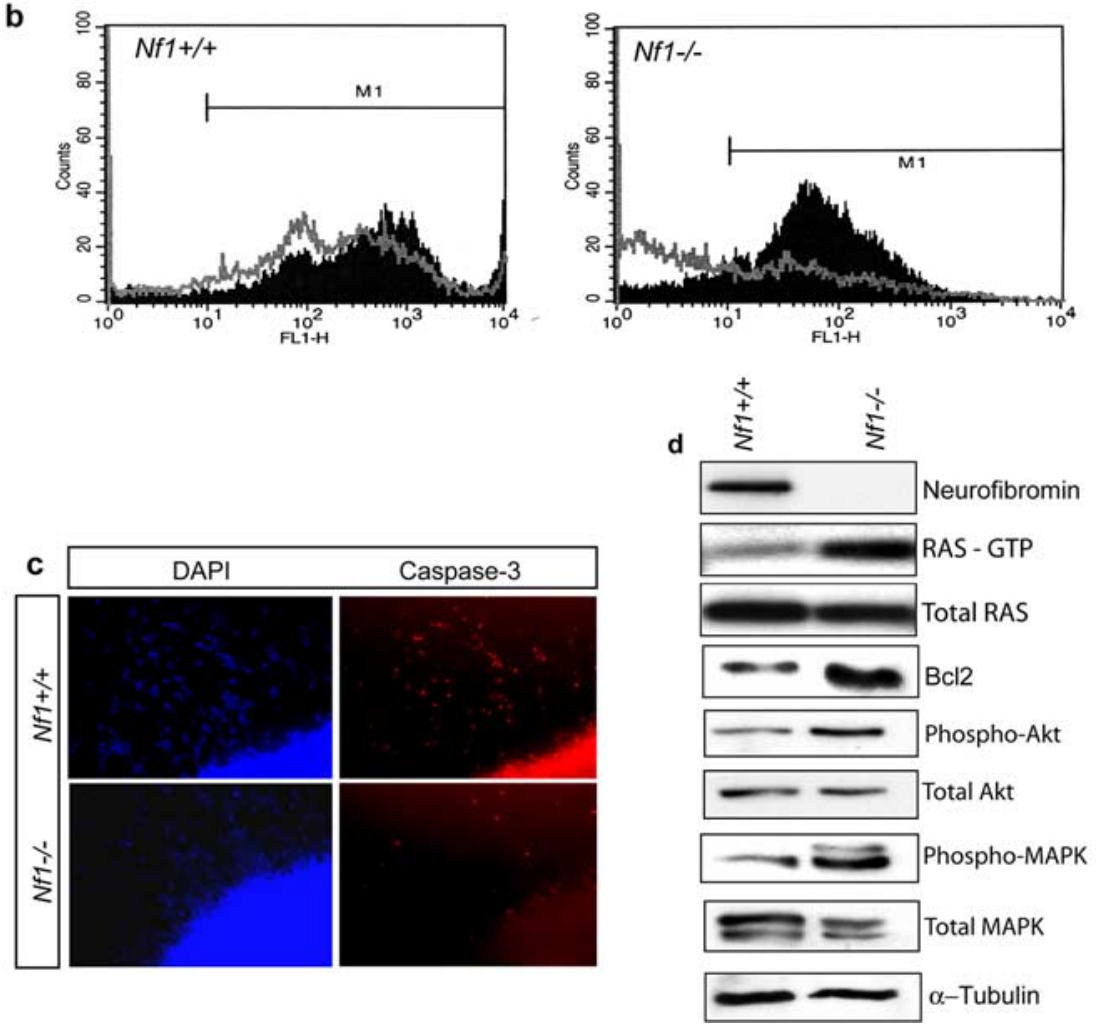

Figure 2. Growth factor-deprived Nf1- - NSCs have increased proliferative and survival advantages in vitro. $a$, Although very few growth factor-deprived Nf1 + I + NSCs (top) incorporated BrdU, a significantly higher number of Nf1 - I - NSCs (bottom) did so under identical conditions ( $p<0.001$ ). The photomicrographs show phase contrast, $4^{\prime}, 6$-diamidino-2-phenylindole (DAPI) (nuclear stain; blue), BrdU (green), and colocalization of DAPI and BrdU (merged; yellow), respectively. $\boldsymbol{b}, \mathrm{Nf1}-1-\mathrm{NSCS}$ exhibit reduced cell-cycle transit time as demonstrated by a shift in CFSE fluorescence $5 \mathrm{~d}$ after labeling compared with $\mathrm{Nf1+} /+$ NSCS (open histogram). CFSE fluorescence at day 1 is shown by filled histograms. c, Staining with an antibody to cleaved (activated) caspase-3 showed decreased apoptosis in growth factor-deprived Nf1-I- NSCs compared with Nf1 + I+ NSCs. $\boldsymbol{d}$, Growth factor-deprived Nf1 - I - NSCs exhibited increased BCI2 expression, hyperactivation of RAS, and increased activation of RAS downstream effectors. Increased expression of BCI2, RAS-GTP, phospho-Akt, and phospho-MAPK in growth factor-deprived Nf1 - I - NSCs relative to Nf1 + I+ NSCs is shown. These blots were stripped and reprobed with antibodies to total Akt and total MAPK. Total RAS is shown as a control for the RAS activity assay. Tubulin is included as an internal control for equal protein loading.

results demonstrate that loss of Nf1 results in a substantial increase in stem cell proliferation and self-renewal in vitro. Moreover, we observed a significant effect of reduced neurofibromin expression (Nf1+/- NSCs) on NSC self-renewal in all of these analyses (Fig. $1 a-e$ ), supporting the hypothesis that $N f 1$ heterozygosity may also influence NSC proliferation and renewal.

We next wanted to determine whether the increased $\mathrm{Nf1}-1-$ NSC self-renewal confers both a survival and proliferative advantage in vitro. To analyze proliferation, we performed BrdU incorporation analysis on growth factor-deprived NSCs. As shown in Figure $2 a, 30 \%$ of $\mathrm{Nf1}-1-\mathrm{NSCs}$ incorporated BrdU (Fig. $2 a$, bottom) compared with $<1 \%$ of similarly treated $\mathrm{Nf1}+\mathrm{I}+$ cells

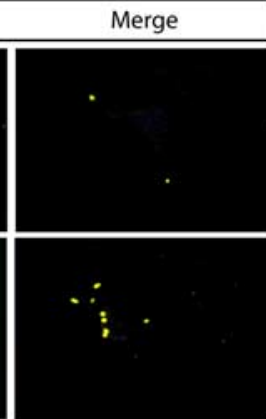

(Fig. 2a, top). In addition, using the CFSE washout method, we observed an increase in the rate of cell division in $\mathrm{Nf1-/-}$ NSCs. Whereas $16.28 \%$ pulse-labeled $\mathrm{Nf1}+$ / + NSCs demonstrated a shift in fluorescence, $70.83 \%$ Nf1-/- NSCs exhibited a fluorescence shift after $5 \mathrm{~d}$ in culture (Fig. 2b), suggesting that Nf1-/- NSCs had passed through a significantly greater number of cell divisions than $\mathrm{Nf1+/+}$ NSCs.

To determine whether neurofibromin loss also conferred a survival advantage, we used activated caspase- 3 immunostaining as a marker of apoptosis. We observed that growth factor-deprived $\mathrm{Nf1-l-}$ NSCs exhibited a $71.06 \pm 18.35 \%$ decrease in activated caspase- 3 immunoreactivity compared with $N f 1+/+$ NSCs (Fig. 2c). Collectively, these data indicate that the dramatic increase in Nf1-/- NSC selfrenewal is attributable both to decreased cell death and increased cell proliferation.

Because neurofibromin functions as a negative regulator of RAS (Ballester et al., 1990; Martin et al., 1990; Xu et al., 1990), we next examined activation of RAS and its downstream effectors in Nf1-/ - NSCs to provide a biochemical correlate for the increased survival and proliferative advantage observed. Growth factor-deprived Nf1-I- NSCs exhibited an approximate sixfold increased RAS activation (RASGTP), approximate threefold increased phospho-Akt expression, approximate eightfold increased phospho-MAPK expression, and approximate sixfold increased expression of the anti-apoptotic protein Bcl2 (Fig. 2d). These findings demonstrate that neurofibromin loss in NSCs results in impaired RAS regulation, as shown previously for $\mathrm{Nfl}-/$ - astrocytes (Bajenaru et al., 2002; Dasgupta et al., 2005).

\section{Loss of $N f 1$ facilitates survival and engraftment of NSCs in vivo}

To provide an in vivo correlate for the in vitro proliferative and survival advantage observed with Nf1-/- NSCs, we wanted to determine whether loss of neurofibromin enabled NSCs to survive and engraft in naive recipient brains in vivo. Previous studies have shown that $\mathrm{Nfl}-/-$ astrocytes were unable to survive or engraft into the cortices of athymic immunocompromised $(n u / n u)$ mice in vivo, and completely disappeared within 1 month after injection (Bajenaru et al., 2003). To determine whether $\mathrm{Nf1-/}$ - NSCs were capable of surviving as explants in vivo, we injected $\beta$-galactosidase-expressing $N f 1+/+$, $\mathrm{Nf1}+/-$, and $\mathrm{Nf1}-/-\mathrm{NSC}$ into the cortex of adult male $n u / n u$ mice. As shown in Figure $3 a, N f 1+/+, N f 1+/-$, and $N f 1-/-$ NSCs could be detected at the injection site $3 \mathrm{~d}$ p.i. However, wild-type NSCs quickly disappeared by 1 month p.i., and only very few LacZ+ cells were found at the injection site. We did not 

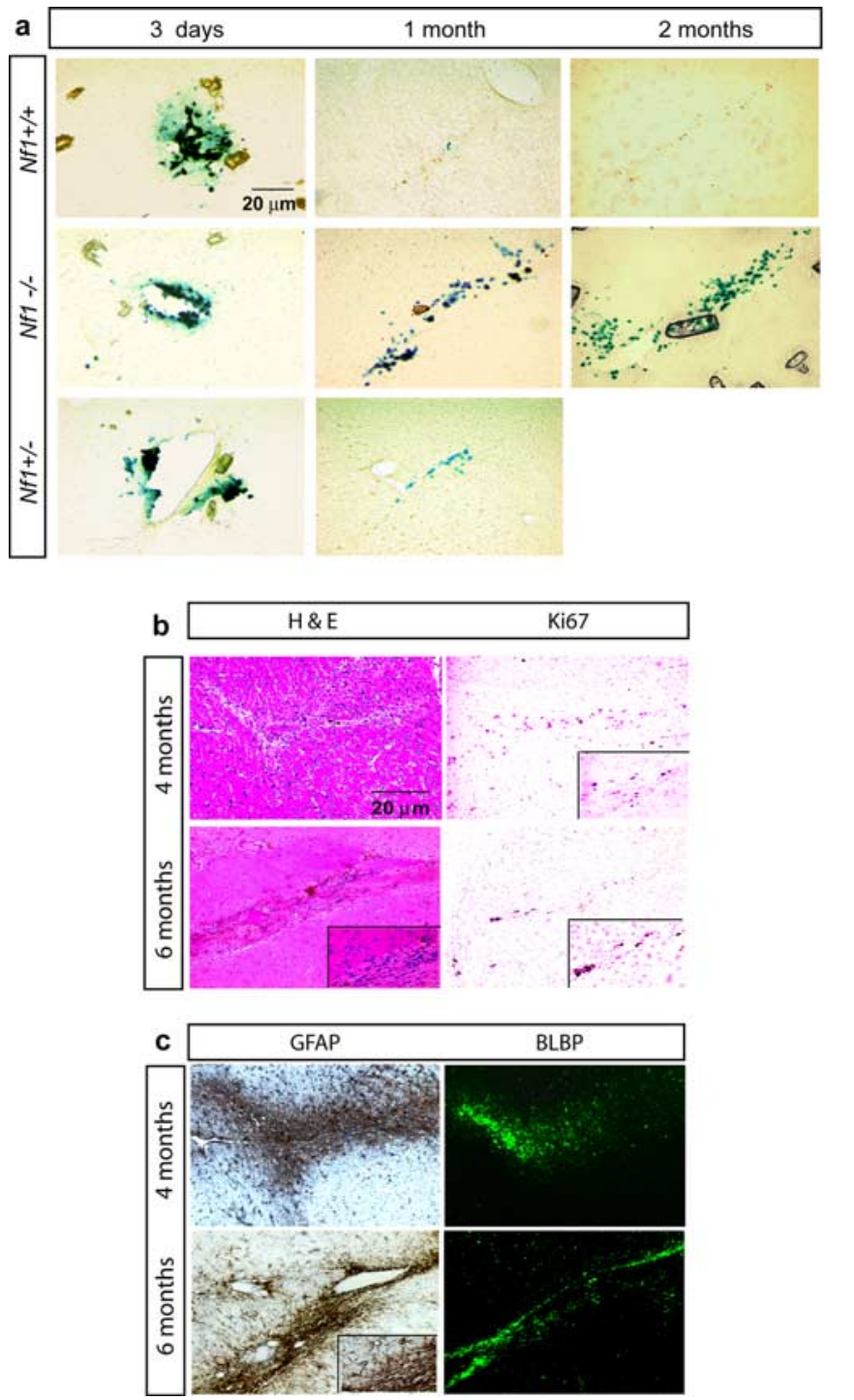

Figure 3. Nf1 - / $-\mathrm{NSCS}$ proliferate and survive as explants and in the brains of immunocompromised mice in vivo. a, A time course cell survival analysis of NSCs in vivo is shown using X-gal staining of representative cortical sections of nu/nu mice brains. Reporter-tagged (LacZ) $\mathrm{Nf1}+/+, \mathrm{Nf1}+/-$, and $\mathrm{Nf1}-/-\mathrm{NSC}$ were found at the injection site $3 \mathrm{~d}$ p.i. Although $\mathrm{Nf1}+$ / + NSCs quickly disappeared from the injection site by 1 month p.i., injected Nf1 - INSCs were found at and around the injection site. Few Nf1 $+/-$ NSCs were observed at the injection tract at 1 month p.i. At 2 months p.i., hardly any Nf1 + / + NSCs could be detected at the injection site. In contrast, Nf1-I- NSCs continued to survive in vivo. $\boldsymbol{b}$, H\&E staining revealed the presence of the injected $N f 1-/$ - cells in the injection tract. Ki67 staining showed proliferating nuclei in the injection tract at 4 and 6 months p.i. c, The injected Nf1-I- NSCs differentiated into GFAP +, BLBP + astrocytes at 4 and 6 months p.i.

observe any LacZ $+N f 1+/+$ NSCs at brain sites distant from the injection site (data not shown). In contrast, many LacZ+ $N f 1-/-$ cells were detected in and around the injection site at 1 month. By 2 months p.i., LacZ $+N f 1+/+$ cells were almost undetectable, whereas large numbers of $N f 1-/-$ cells were clearly visible in and around the injection tract. Moreover, we detected isolated or occasional groups of four to five LacZ $+N f 1-/-$ cells distant from the injection site, with some $\mathrm{Nf1}-/$ - cells detected in the contralateral cortex (data not shown).

Analysis of the brains from mice implanted with $\mathrm{Nf1}+/-$ NSCs demonstrated the presence of a small number of scattered LacZ + cells in the injection tract at 1 month p.i. but there were significantly fewer cells than observed in mice given injections of Nf1-I- NSCs.

Next, we wanted to determine whether the injected $\mathrm{Nf1}-$ /NSCs were proliferating in the recipient brains. Injection tracts of $N f 1-/-$ NSCs were identified by H\&E staining of cortical sections (Fig. $3 b$ ). To identify proliferating cells in the injection tract, we performed Ki67 immunohistochemical analysis. Clusters of $\mathrm{Ki} 67+$ cells were detected in the injection tract at 4 and 6 months p.i. (Fig. 3b). No Ki67 immunoreactivity was detected in the cortex of $n u / n u$ mice given injections of $N f 1+/+$ NSCs (data not shown).

To determine whether the engrafted NSCs were able to differentiate, cortical sections at 4 and 6 months p.i. were stained for expression of GFAP (astroglial cells), CD44 [astrocyte-restricted precursor (Liu et al., 2004)] and BLBP [astroglial progenitors (Feng et al., 1994)]. Robust GFAP and BLBP immunoreactivity was detected in and around the injection tract at 4 and 6 months p.i of Nf1-/- NSCs (Fig. 3c). In contrast, no CD44 immunoreactivity was observed (data not shown). We observed no change in the intensity of GFAP expression from 4 to 6 months p.i.; however, BLBP expression was reduced or absent in most GFAP + cells at 6 months p.i., suggesting the possibility that these $\mathrm{BLBP}+$, GFAP $+N f 1-/-$ immature astrocytes continue to differentiate in vivo. No intensely stained GFAP + or BLBP + cells were detected in the cortex of $n u / n u$ mice given injections of $N f 1+/+$ NSCs. We did not observe any histological evidence for tumor formation in mice given injections of Nf1-/ - NSCs even after 12 months (data not shown).

To determine whether these NSCs also differentiated into neurons, we stained the injected brain sections with antibodies to NeuN and MAP2 (data not shown). No neuronal nuclei or processes were identified in the injection tract, suggesting that the Nf1-/ - NSCs differentiated into astrocytes and not neurons. Collectively, these results demonstrate that $N f 1$ loss results in the generation of a persistent population of $\mathrm{GFAP}+, \mathrm{BLBP}+$ proliferating cells, which could serve as a source for preneoplastic cells important for NF1-associated glioma formation.

\section{Nf1 loss in NSCs does not impair multi-lineage}

\section{differentiation but alters astroglial cell differentiation.}

Like wild-type NSCs, undifferentiated $\mathrm{Nf1}-\mathrm{I}-$ and $\mathrm{Nf1}+\mathrm{I}-$ NSCs robustly expressed NSC markers, including nestin and CD133 (data not shown). To determine whether neurofibromin loss in NSCs affects the ability of these stem cells to differentiate into astroglial cells, we allowed EGF/FGF-expanded NSCs to differentiate into neurons and glia on growth factor withdrawal. After growth factor withdrawal, NSCs of all three genotypes differentiated into GFAP+ astrocytes, Tuj1+ neurons, and $\mathrm{O} 4+$ oligodendrocytes.

We observed no differences in the relative numbers of astrocytes or neurons between $\mathrm{Nf1}+/+, \mathrm{Nf1}+/-$, and $\mathrm{Nf1}-/-\mathrm{NSCs}$ (Fig. $4 a$ ); however, we found a $24 \%$ increase in oligodendrocytes generated by $\mathrm{Nf1}-/-\mathrm{NSCs}$. This increase in oligodendrocyte production is consistent with recent results obtained using $\mathrm{Nf1-/}$ - spinal cord-derived progenitor cells (Bennett et al., 2003).

Although Nf1+/+ NSCs differentiated into large morphologically distinct GFAP + cells characteristic of differentiated astrocytes, Nf1-I- NSCs gave rise to thin GFAP+ cells with long filamentous extensions (Fig. 4b). The GFAP + cells that differentiated from $\mathrm{Nf1}+\mathrm{I}-\mathrm{NSCs}$ exhibited a phenotype intermediate between $\mathrm{Nf1}+/+$ and $\mathrm{Nf1}+/-\mathrm{NSCs}$, although the filamentous appearance of $N f 1-/-$ astrocytes was less apparent in these cells. 


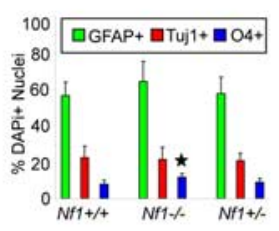

b
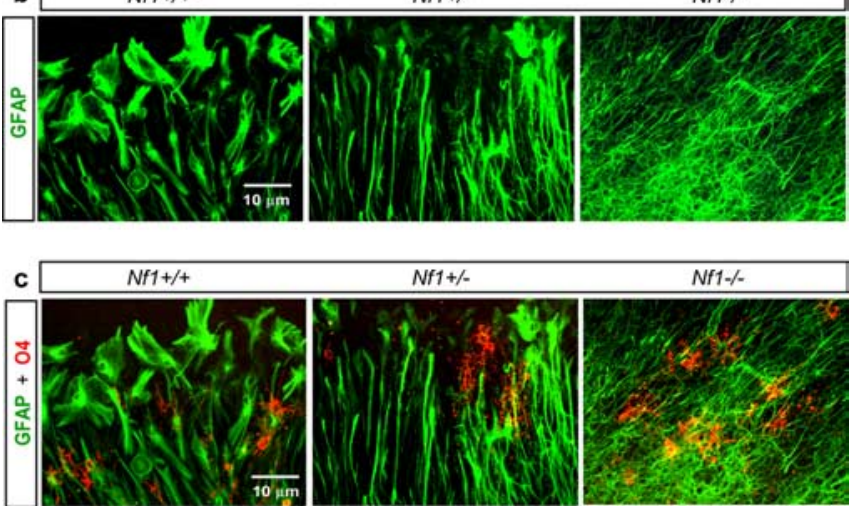

Figure 4. Nf1-/ $\mathrm{NSCS}$ undergo multilineage differentiation. $\boldsymbol{a}$, No differences in the relative numbers of astrocytes and neurons were observed between $\mathrm{Nf1}+\mathrm{I}+, \mathrm{Nf1}+\mathrm{I}-$, and Nf1-I- cells. However, a $24 \%$ increase in $04+$ cells was detected in differentiating Nf1 - / - NSCs compared with wild-type NSCs. $\boldsymbol{b}$, Although Nf1 + I+ NSCs differentiated into morphologically distinct astrocytes, Nf1-I- NSCs gave rise to an arborous network of fibrillary-appearing astrocytes. Nf1 + / - NSCs exhibited an intermediate phenotype. C, Although $\mathrm{Nf1}+\mathrm{I}+, \mathrm{Nf1}-\mathrm{I}-$, and Nf1 $+/-\mathrm{NSC}$ differentiated into morphologically similar $04+$ oligodendrocytes, a subpopulation of 04-expressing Nf1 - / - cells coexpressing GFAP were also detected

No significant differences in oligodendrocyte morphology were observed between $\mathrm{O} 4+\mathrm{Nf1}+/+$ and $\mathrm{Nf1}-/-$ cells; however, a subpopulation of $\mathrm{Nf1}-\mathrm{I}-\mathrm{O} 4+$ cells were detected that also coexpressed GFAP (Fig. $4 c$ ).

Because Nf1-/ - NSCs generated GFAP + cells, which morphologically resembled immature glia, we performed immunohistochemical analyses using antibodies to BLBP, vimentin, CD44, and RC2, which represent markers of astroglial progenitors and immature astroglia. As shown in Figure 5, Nf1+/+ cells robustly expressed GFAP with little expression of BLBP ( $a$, top), vimentin ( $b$, top), or RC2 ( $c$, top). In contrast, Nf1-/- GFAP+ cells robustly expressed all the three markers of immature astrocytes [BLBP (Fig. $5 a$, bottom); vimentin (Fig. $5 b$, bottom); RC2 (Fig. 5c, bottom)]. Neither $\mathrm{Nf1}+/+, \mathrm{Nf1}+/-$ nor $\mathrm{Nf1-l-}$ $\mathrm{GFAP}+$ cells expressed CD44 after in vitro differentiation (data not shown).

\section{Hyperproliferation and altered astroglial differentiation in Nf1-/- NSCs is rescued by expressing the GRD of neurofibromin}

To determine whether the dramatic increases in self-renewal and proliferation of $\mathrm{Nf1}-/ \mathrm{-}$ NSCs were the direct result of loss of neurofibromin GTPase-activating domain function, we infected Nf1-/- NSCs with MSCV-Pac (vector control), MSCVNF1GRD (NF1-GAP domain; residues 1172-1538), or MSCVNF1GRD R1276P (NF1GRD with no RASGAP activity resulting from presence of an NF1 patient mutation). In these experiments, we found that NF1GRD expression reduced the proliferation (Fig. 6a) and self-renewal (Fig. 6b) observed in Nf1-/NSCs to levels similar to wild-type NSCs (77.33 and 80.2\%, respectively) at $96 \mathrm{~h}$ after seeding. No changes in proliferation or
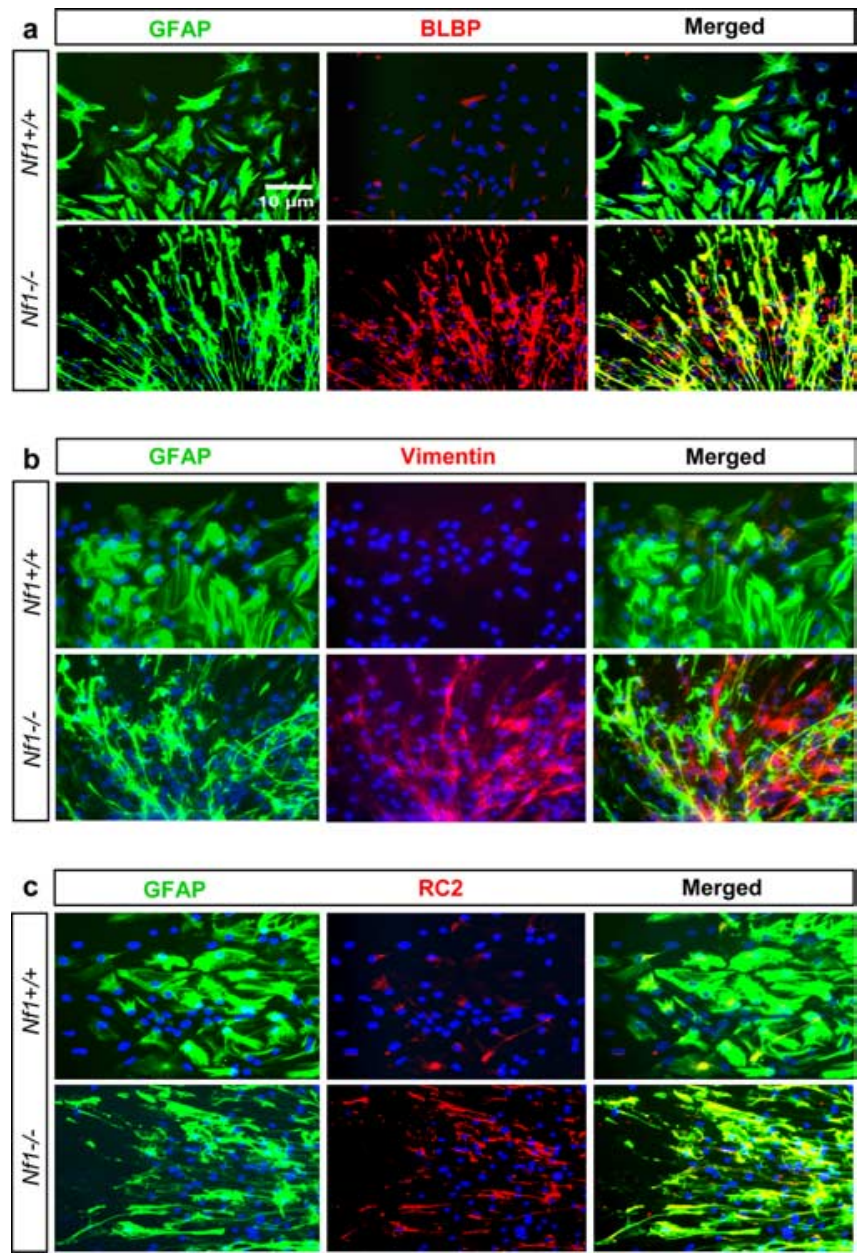

Figure 5. Loss of Nf1 leads to impaired NSC glial differentiation in vitro. Nf1 +/ + NSCS differentiated into mature astrocytes, all of which exclusively or primarily expressed GFAP (green). In contrast, the GFAP + cells that differentiated from Nf1-I- NSCs robustly coexpressed BLBP, vimentin, and RC2 (markers of immature astrocytes). $\boldsymbol{a}$, Immunofluorescence staining of $\mathrm{NF1+/}+$ and $\mathrm{Nf1}-/$ - cells expressing GFAP (green), BLBP (red), and colocalization (merged; yellow). $\boldsymbol{b}$, GFAP (green) and vimentin (red) expression and colocalization (merged; yellow) by Nf1 + I+ and Nf1 - / - cells. c, Expression of GFAP (green), RC2 (red), and their colocalization (merged; yellow) by Nf1 $+/+$ and Nf1-I- cells. Nuclei in all cases were stained with 4',6-diamidino-2-phenylindole.

self-renewal were observed in Nf1 - / - cells infected with MSCVPac or MSCV-NF1GRD R1276P or in Nf1+/+ cells infected with either MSCV-Pac or MSCV-NF1GRD.

To provide additional support for the role of RAS pathway activation in Nf1-/ - NSC hyperproliferation, we wanted to determine whether $\mathrm{Nf1}-/-$ NSC hyperproliferation could be reversed by pharmacological inhibition of MEK kinase. In these experiments, $N f 1-/-$ NSCs were treated with the MEK inhibitor PD98059 at pharmacological doses shown previously to restore Nf1-/- MEK hyperactivation to wild-type levels (data not shown). Treatment of Nf1-/ - NSCs with $20 \mu \mathrm{M}$ PD98059 reduced the proliferation (Fig. 6a) and self-renewal (Fig. 6b) by 84.5 and $86.2 \%$, respectively. This level of inhibition was comparable with that observed after the expression of the NF1GRD. The PI3K inhibitor LY294002 (at both 10 and $20 \mu \mathrm{M}$ concentrations) severely affected survival of NSCs of all genotypes to comparable levels (data not shown).

Because both increased self-renewal and proliferation of Nf1-/ - NSCs could be reverted by introducing the NF1GRD, we tested whether NF1GRD expression could restore the normal 
activation or expression state of these RAS pathway effectors. After introduction of the NF1GRD, the expression of $\mathrm{Bcl} 2$, phospho-Akt and phospho-MAPK (Fig. 6c) reverted to wild-type levels.

To determine whether the defect in astroglial differentiation reflected loss of NF1GRD function, we allowed Nf1-/NSCs expressing NF1GRD to undergo differentiation in vitro. As shown in Figure $6 d$, in contrast to NSCs infected with MSCV-Pac (control) virus, expression of the NF1GRD completely rescued the Nf1 - / - NSC astroglial cell differentiation abnormalities. After NF1GRD expression, Nf1-/ - GFAP + cells became morphologically distinct and expressed almost exclusively GFAP with dramatic reductions in BLBP expression.

We have shown previously that $\mathrm{Nf1}-\mathrm{I}-$ astrocytes have reduced G-proteinstimulated cAMP generation, which could be rescued by the addition of exogenous cAMP (Dasgupta et al., 2003). However, long-term exposure to cAMP at concentrations sufficient to restore reduced cAMP function in $\mathrm{Nf1}-/-$ astrocytes had no effect on the increased proliferation, self-renewal, or aberrant glial differentiation of Nf1-/ - NSC (data not shown). Collectively, these results demonstrate that the ability of neurofibromin to modulate NSC proliferation, survival, and differentiation is regulated by sequences contained with the NF1GRD and reflects neurofibromin RAS regulation.

$N f 1$ heterozygosity in NSCs also results in defects in glial cell differentiation Because the brains of children with NF1 develop from NF1+/- progenitor cells, we examined GFAP + astrocytes differentiated from $\mathrm{Nf1}+/$ - NSCs from multiple embryos. Between 38 and $60 \%$ of GFAP+ $N f 1+/-$ glial colonies exhibited long filamentous processes similar to $\mathrm{Nf1}-/$ - glial cells and expressed BLBP, in contrast to $\mathrm{Nf1}+/+\mathrm{GFAP}+$ astrocytes, which showed little BLBP expression. Representative fields of differentiating GFAP+ $\mathrm{Nf1}+/+$ (top) and GFAP,$+ \mathrm{BLBP}+$ $\mathrm{Nf1}+/-$ astrocytes (bottom) are shown in Figure 7. Collectively, these results raise the possibility that glial differentiation defects can result from $N f 1$ heterozygosity.

\section{Neurofibromin regulates NSC number and proliferation in vivo}

Based on the observed abnormalities in proliferation, survival, and astroglial cell differentiation in both $\mathrm{Nf1}+\mathrm{I}-$ and $\mathrm{Nf1}-\mathrm{I}-$ NSCs in vitro, we hypothesized that there would be increased cell proliferation and more neural stem/progenitor cells in $\mathrm{Nf1-I-}$ and $N f 1+/-$ embryonic brains in vivo. To provide an in vivo correlate for our in vitro findings, we analyzed frozen sections of shown). b

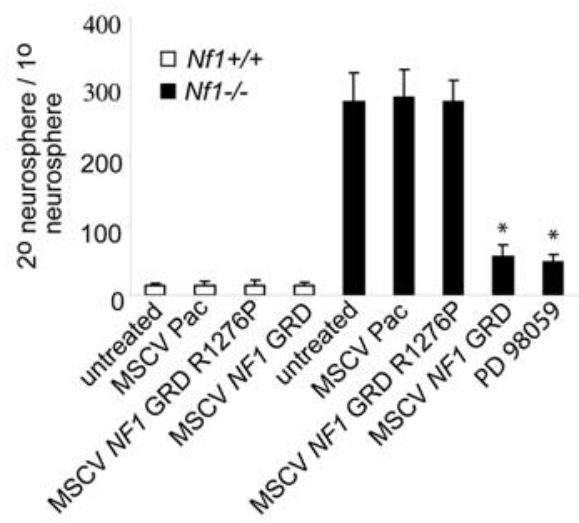

d

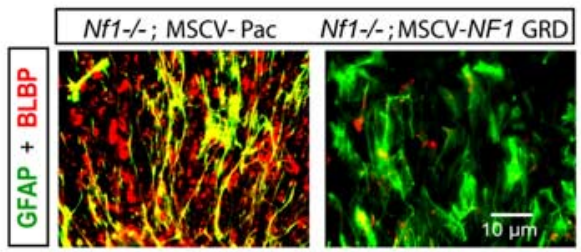

Figure 6. Ectopic expression of the NF1GRD rescues hyperproliferation and altered glial differentiation of Nf1-/ - NSCS. Ectopic expression of the NF1 RASGAP-related domain (NF1GRD; inset), but not a nonfunctional NF1GAP domain (NF1GRDR1276P; inset), significantly reduced proliferation $(\boldsymbol{a} ; p<0.005)$ and self-renewal $(\boldsymbol{b} ; p<0.001)$ of Nf1-I-NSCS. The MEK kinase inhibitor PD98059 $(20 \mu \mathrm{m})$ also significantly inhibited both hyperproliferation and increased self-renewal of Nf1 - / - NSCs to MAPK activation was observed in either Nf1-/ - or Nf1+/+ NSCS after MSCV-Pac infection. All blots were stripped and Nf1 - / - astrocytes that differentiated from Nf1 - I - NSCs (left). Rescue of Nf1 - / - NSCs infected with MSCV-NF1GRD (right) parable with that observed in wild-type cells. Nf1 - I - NSCs infected with control virus (MSCV-Pac) showed robust expression of BLBP along with GFAP in astrocytes (left), similar to astrocytes that differentiated from uninfected Nf1 - / - NSCS (data not shown). Infection of wild-type NSCs with either control virus or MSCV-NF1GRD did not alter the astrocyte phenotype (data not

embryonic brains at day 12.5 , because $N f 1$ loss results in embryonic lethality by E13.5. We used antibodies against Sox2, Olig1, $\mathrm{NKx} 2.2$, and BLBP to identify stem/progenitor cells. Immunohistochemistry revealed significantly increased numbers of Sox $2+$ cells in the neural tube and in the margins of lateral ventricles of $\mathrm{Nf1}-\mathrm{I}-$ embryos, compared with wild-type embryos (Fig. 8a). Importantly, the developing brains of $N f 1+/-$ mice also contained more Sox $2+$ cells than $\mathrm{Nf1}+/+$ embryos. Although very few BLBP + cells were observed in the neural tube of $N f 1+/+$ embryos, numerous BLBP + cells were observed in the neural tubes of the $N f 1+/-$ and $N f 1-/-$ embryos (Fig. 8a). Similarly, we also observed considerably higher numbers of 


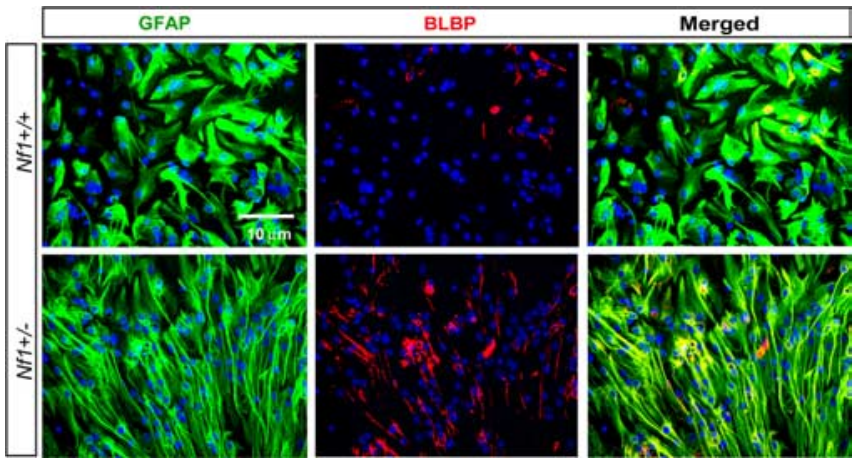

Figure 7. Nf1 +/ - NSCs exhibit abnormal astroglial differentiation. Wild-type NSCs differentiated into GFAP + flat astrocytes that mostly lacked BLBP expression (top). In contrast, Nf1 + I - NSCs differentiated into a mixture of both morphologically distinct flat GFAP + cells and filamentous GFAP + cells (green). UnlikeNf1 + I+ GFAP + cells, Nf1 + I- cells expressed varying levels of BLBP (red; bottom). Nuclei were counterstained with 4',6-diamidino2-phenylindole.

$\mathrm{Nkx} 2.2+$ and Olig1+ glial precursors in the neural tube from $\mathrm{Nf1}+/-$ and $\mathrm{Nf1}-/-$ embryos compared with $\mathrm{Nf1}+/+$ embryos (Fig. 8a). To determine whether increased numbers of neuronal progenitors were found in $\mathrm{Nf1}-\mathrm{I}-$ or $\mathrm{Nf1}+/$ - embryonic brains, we performed immunohistochemistry with Tuj1 and doublecortin antibodies. We did not observe any reproducible differences in the numbers of Tuj1 + or doublecortin + cells in $N f 1+/-$ or $N f 1-/-$ embryo brains relative to $N f 1+/+$ embryos (data not shown).

Because $\mathrm{Nf1}-\mathrm{I}-$ embryos die in utero, we next wanted to determine whether more proliferating cells persist in the brains of adult $N f 1+/-$ mice. As shown in Figure $8 b$, increased numbers of BrdU+, proliferating cells were observed in the subventricular zone (twofold increase) and in the hippocampus (fivefold increase) of $\mathrm{Nf1}+/$ - mice compared with wild-type mice. In addition, we did not observe any reproducible differences in the numbers of Tuj $1+$ or MAP $2+$ cells in adult $N f 1+/$ - brain compared with control wild-type littermates (data not shown). Together, these results demonstrate that increased numbers of neural stem/ progenitor cells result from dose-dependent decreases in neurofibromin expression, which likely lead to the formation of a persistent population of proliferating cells in the brains of adult $N f 1+/-$ mice.

\section{Discussion}

Much of our understanding of the function of neurofibromin derives from studies focused on NF1 growth regulation and its relationship to tumor formation. In this regard, NF1 loss in vivo is associated with neurofibroma formation (Cichowski et al., 1999), malignant peripheral nerve sheath tumor development (Vogel et al., 1999), and leukemogenesis (Bollag et al., 1996; Largaespada et al., 1996; Birnbaum et al., 2000). Nf1-/- Schwann cells (neurofibromas and malignant peripheral nerve sheath tumor) and myeloid cells (leukemia) exhibit increased cell proliferation in vitro and in vivo. In contrast, there is considerably less known about the role of neurofibromin in progenitor cell growth regulation within the CNS. Consistent with the function of neurofibromin as a negative growth regulator, we show that both reduced $(\mathrm{Nf1}+/-)$ and absent $(\mathrm{Nf1}-/-)$ neurofibromin expression in NSCs lead to increased stem cell proliferation. Although there is a clear effect of $N f 1$ haploinsufficiency (3-fold increase over wildtype cells), the most dramatic effects were seen in Nf1-deficient cells (12-fold increase). Similar analyses of NSCs from Pten-/-
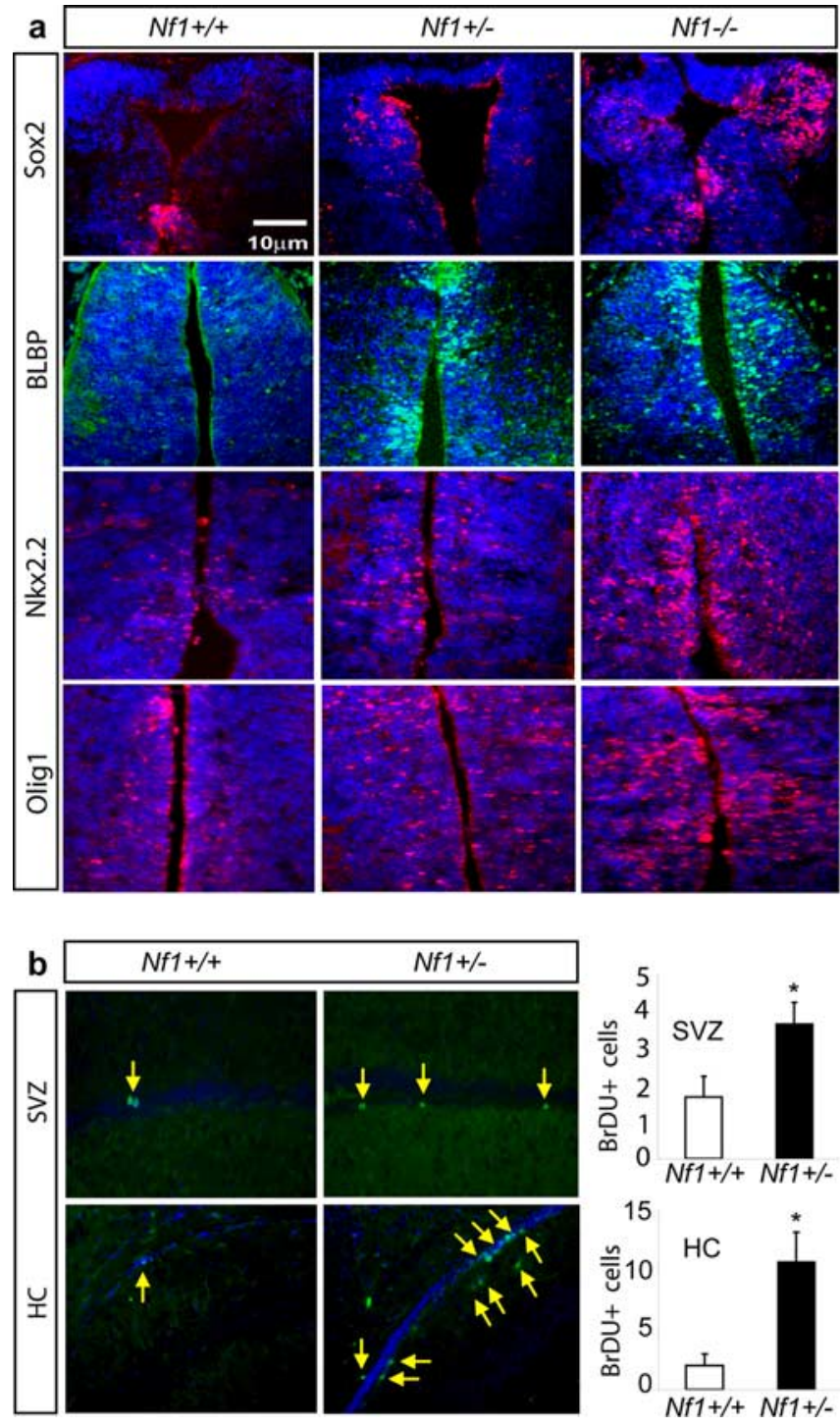

Figure 8. Altered neurofibromin expression results in increased neural stem/progenitor cells in the brains of $N f 1+1-$ and $N f 1-1-$ mice in vivo. $a$, Immunolocalization of neural stem and progenitor cells in the embryonic brains (E12.5) of $\mathrm{Nf1}+\mathrm{I}+, \mathrm{Nf1}+\mathrm{I}-$, and $\mathrm{Nf1}-\mathrm{I}-$ mice. Increased numbers of Sox2+, BLBP,$+ \mathrm{Nkx2.2+}$, and 0lig1 + cells were observed in the developing brains of both $N f 1+/-$ and $N f 1-/-$ mice compared with embryonic brains of $\mathrm{Nf1}+/+$ mice. $\boldsymbol{b}$, Persistent populations of proliferating cells were observed in the brain of adult Nf1+/ - mice (arrows). BrdU + proliferating cells are shown in the subventricular zone (SVZ) and hippocampus (HC) of $N f 1+I+$ and $N f 1+1-$ mice. The number of BrdU + cells were calculated for each region in $\mathrm{Nf1}+1+$ and $\mathrm{Nf1}+/-$ mice. There were significantly more proliferating cells in the SVZ $(p<0.005)$ and HC $(p<0.001)$ of $N f 1+/-$ mice compared with $\mathrm{Nf1}+/+$ mice. Nuclei were counterstained with 4',6-diamidino-2-phenylindole.

mice revealed a fivefold increase in self-renewal over wild-type NSCs (Groszer et al., 2001). Compared with Pten, Nf1-/- NSCs showed $\sim 10$-fold increase in self-renewal over wild-type NSCs, suggesting that neurofibromin may play a more significant role in regulating stem cell self-renewal and proliferation in the developing brain.

Previous studies have suggested that neurofibromin exerts its primary effect on cell growth by modulating mitogenic signaling pathways downstream of RAS. Consistent with this finding, we observed hyperactivation of RAS and two of its downstream effectors, MAPK and Akt. These signaling abnormalities are reflected by both an increase in cell proliferation (Raf-MAPK) and a decrease in cell death (Akt). Surprisingly, we observed increased 
expression of the antiapoptotic Bcl2 protein in Nf1-/- NSCs, suggesting the possible contribution of both Akt and $B c l 2$ to increased cell survival. This is the first report of $B c l 2$ overexpression in a cell with $N f 1$ loss of function. The reversal of $B c l 2$ expression to wild-type levels after NF1GRD expression in Nf1-/- NSCs supports a RAS-dependent mechanism for regulating $B c l 2$ and modulating programmed cell death (apoptosis). These observations are consistent with studies in which inducible oncogenic RAS expression resulted in upregulation of $B c l 2$ expression, reduced apoptosis, and increased survival of hematopoietic cells (Kinoshita et al., 1995). Previous data from our laboratory on Nf1-/ - postnatal astrocytes demonstrated that neurofibromin loss results in impaired cAMP generation (Dasgupta et al., 2003). Because cAMP treatment of Nf1-/ - NSCs at concentrations sufficient to restore cAMP-dependent functions in $\mathrm{Nf1}-\mathrm{I}-$ astrocytes did not reduce $N f 1-/-$ NSC self-renewal, it is unlikely that the cAMP regulatory function of neurofibromin significantly contributes to the growth properties of Nf1-/ - NSCs and that these biological effects are mediated by neurofibromin RAS regulation. These observations are consistent with our previous findings in which activated K-RAS (which does not impair intracellular cAMP generation in astrocytes) can substitute for Nf1 loss in the formation of optic glioma in vivo (Dasgupta et al., 2005).

In addition to abnormal growth control in Nf1-/ - NSCs, we observed both morphological and immunochemical changes suggestive of an immature glial phenotype resulting from $N f 1$ inactivation. The glia that derive from $N f 1-/-$ NSCs exhibit long filamentous processes, and many of the cells express markers typically associated with glial precursors, including BLBP, RC2, and vimentin. It is worth noting that human gliomas often express such glial precursor markers suggestive of the possible presence of immature progenitor cells within the tumors (Abaza et al., 1998). Similar to the growth defects, dysregulated RAS activity likely accounts for these abnormalities in glial differentiation, because inhibiting RAS activity using pharmacological inhibitors (data not shown) or by expressing the neurofibromin RAS-GAP domain (NF1GRD) corrected the Nf1-I- NSC astroglial differentiation defect.

Another property of $\mathrm{Nf1}-/$ - NSCs was their ability to persist as focal collections of hyperproliferating cells in the injection tract for $>6$ months. In contrast to wild-type NSCs, Nf1-/embryonic (E12) astrocytes, or postnatal (P1-P2) Nf1-/- astrocytes, Nf1-/ - NSCs exhibited long-term survival in vivo. These results raise the possibility that Nf1 inactivation in NSCs or astroglial progenitors leads to the generation of a small population of atypical stem cells with the ability to aberrantly proliferate and survive for long periods of time in the adult brain and potentially serve as a reservoir of "preneoplastic" cells. Despite the lack of obvious tumor formation after 1 year, these progenitor cells may represent targets for additional genetic or cellular changes that might lead to glioma development. Finally, we noted that Nf1-/ - NSCs were found at sites distal from the original injection, including the contralateral hemisphere. These observations suggest that a small number of $N f 1-/-$ progenitor cells are capable of widely disseminating throughout the brain and establishing themselves as stem cells with dramatic self-renewal, proliferative, and survival advantages over wild-type cells.

The expansion of Sox $2+$, BLBP + , Olig1+, and Nkx2.2+ stem/progenitor cells in the developing $N f 1-/-$ brain suggests that partial or complete neurofibromin loss in the neural progenitor cells contributes to the abnormal proliferation and differentiation of these cells in vivo. Expression of the Sox 2 transcription factor is a molecular signature of proliferating stem/progenitor cells, and Sox2 expression is necessary for maintaining neural stem/progenitor cell identity (Uwanogho et al., 1995; Graham et al., 2003). Similarly, BLBP is expressed as early as E10 in multipotent proliferating cells within the CNS, which are thought to represent progenitors of astroglial cells (Feng et al., 1994; Li et al., 2004). Finally, both Olig1 and Nkx2.2 are expressed in cells within the developing neural tube (Lu et al., 2000; Zhou et al., 2001; Liu et al., 2004). Based on our findings, we propose that loss of neurofibromin in NSCs results in the expansion of progenitors that contribute to the abnormal CNS features seen in individuals with NF1. As has been proposed previously for other genes involved in astroglial cell differentiation, such as $p 27^{k i p 1}$ (CasacciaBonnefil et al., 1999) or Pten (Groszer et al., 2001), reduced or absent expression of the neurofibromin tumor suppressor results in abnormal brain development. In this regard, $12.5 \%$ of $\mathrm{Nf1}$-/ - embryos exhibited gross defects of cranial neural tube closure, including exencephaly (Lakkis et al., 1999).

We observed a moderate, yet significant increase in proliferation and self-renewal of $\mathrm{Nf1}+/-\mathrm{NSCs}$ and aberrant expression of the immature glial marker BLBP in GFAP $+\mathrm{Nf1}+/-$ astrocytes in vitro. Our in vitro observations are corroborated by the presence of increased numbers of neural progenitors in the embryonic $N f 1+$ / - brain. We hypothesize that these $N f 1+/$ - cells also have the potential to proliferate aberrantly during $\mathrm{Nf1}+\mathrm{I}-$ brain development. Consistent with this notion, we observed more proliferating cells in the adult $N f 1+/-$ brain. There are two potential scenarios in which increased numbers of $N F 1+/-$ progenitors might result in NF1-associated clinical brain abnormalities. First, the retention of increased numbers of proliferating stem/progenitor cells in NF1 + / human brains during development and their persistence in the adult brain would increase the statistical likelihood of undergoing inactivation of the one remaining NF1 allele. Homozygous loss of NF1 expression would then result in elevated RAS pathway activation and neoplastic transformation, culminating in glioma formation. Although it is not clear that cancer stem cells are equivalent to NSCs, these cancer-associated progenitor cells are multipotent and have the ability to self-renew like NSCs. Moreover, these cancer stem cells, when re-implanted into the brains of naive recipient rodents, can recapitulate the original tumor, suggesting that these cells might possess all of the required cellular and genetic changes sufficient for tumorigenesis and might be a logical target for anticancer therapy. Given the similarities between NSCs and cancer stem cells, future experiments might use Nf1-/- NSCs as a manipulable system for NF1 tumor modeling studies.

Second, because the brains of children with NF1 develop from $N F 1+/-$ stem cells, small impairments in stem/progenitor cell function might have profound implications for normal brain development. In this regard, over one-half of children with NF1 have cognitive deficits and learning disabilities (North et al., 1997), and most have significantly enlarged heads (Clementi et al., 1999). Although we did not notice any gross morphological abnormalities in the neurons from either embryonic $N f 1-/-$ or adult $N f 1+/-$ brains in vivo, we did observe shorter neurites in Tuj1+ neurons that differentiated from $\mathrm{Nf1}+/-$ and $\mathrm{Nf1-I-}$ neurospheres in vitro (data not shown). Moreover, we did not observe any reproducible differences in the numbers of Tuj $1+$ or $\mathrm{MAP} 2+$ cells in adult $\mathrm{Nf1}+/-$ mouse brains (data not shown). In light of the elegant studies by Costa et al. (2002) demonstrating that $\mathrm{Nf1}+/-$ neurons in situ have increased GABA-mediated inhibition and that $\mathrm{Nf1}+/-$ mice exhibit defects in long-term potentiation, future experiments will be needed to analyze the 
functional properties of the $N f 1+/-$ neurons with shortened neuritic processes detected in the present study.

In summary, the present report demonstrates a dosedependent effect of Nf1 loss on NSC proliferation, survival, selfrenewal, and differentiation in vitro and in vivo. These findings suggest that NF1 heterozygosity in progenitor cells during brain development and even in the adult CNS (Sanai et al., 2004) may result in a predisposition to glioma formation. The ability to model these phenotypes in vitro and in vivo provides a unique opportunity to define the molecular basis for the nervous system abnormalities seen in patients with NF1.

\section{References}

Abaza MS, Shaban F, Narayan RK, Atassi MZ (1998) Human gliomas associated intermediate filament proteins: over-expression, co-expression, co-localization and cross-reactivity. Anticancer Res 18:1333-1340.

Al-Hajj M, Wicha MS, Benito-Hernandez A, Morrison SJ, Clarke MF (2003) Prospective identification of tumorigenic breast cancer cells. Proc Natl Acad Sci USA 100:3983-3988.

Arsenijevic Y, Weiss S, Schneider B, Aebischer P (2001) Insulin-like growth factor-I is necessary for neural stem cell proliferation and demonstrates distinct actions of epidermal growth factor and fibroblast growth factor- 2 . J Neurosci 21:7194-7202.

Bajenaru ML, Donahoe J, Corral T, Reilly KM, Brophy S, Pellicer A, Gutmann DH (2001) Neurofibromatosis 1 (NF1) heterozygosity results in a cellautonomous growth advantage for astrocytes. Glia 33:314-323.

Bajenaru ML, Zhu Y, Hedrick NM, Donahoe J, Parada LF, Gutmann DH (2002) Astrocyte-specific inactivation of the neurofibromatosis 1 gene (NF1) is insufficient for astrocytoma formation. Mol Cell Biol 22:5100-5113.

Bajenaru ML, Hernandez MR, Perry A, Zhu Y, Parada LF, Garbow JR, Gutmann DH (2003) Optic nerve glioma in mice requires astrocyte Nf1 gene inactivation and $N f 1$ brain heterozygosity. Cancer Res 63:8573-8577.

Bajenaru ML, Garbow JR, Perry A, Hernandez MR, Gutmann DH (2005) Natural history of neurofibromatosis 1-associated optic nerve glioma formation in mice. Ann Neurol 57:119-127.

Ballester R, Marchuk D, Boguski M, Saulino A, Letcher R, Wigler M, Collins F (1990) The NF1 locus encodes a protein functionally related to mammalian GAP and yeast IRA proteins. Cell 63:852-859.

Bennett MR, Rizvi TA, Karyala S, McKinnon RD, Ratner N (2003) Aberrant growth and differentiation of oligodendrocyte progenitors in neurofibromatosis type 1 mutants. J Neurosci 23:7207-7217.

Birnbaum RA, O’Marcaigh A, Wardak Z, Zhang YY, Dranoff G, Jacks T, Clapp DW, Shannon KM (2000) Nf1 and Gmcsf interact in myeloid leukemogenesis. Mol Cell 5:189-195.

Bollag G, Clapp DW, Shih S, Adler F, Zhang YY, Thompson P, Lange BJ, Freedman MH, McCormick F, Jacks T, Shannon K (1996) Loss of NF1 results in activation of Ras signaling pathway and leads to aberrant growth in hematopoietic cells. Nat Genet 12:144-148.

Brannan CI, Perkins AS, Vogel KS, Ratner N, Nordlund ML, Reid SW, Buchberg AM, Jenkins NA, Parada LF, Copeland NG (1994) Targeted disruption of the neurofibromatosis type-1 gene leads to developmental abnormalities in heart and various neural crest-derived tissues. Genes Dev 8:1019-1029.

Casaccia-Bonnefil P, Hardy RJ, Teng KK, Levine JM, Koff A, Chao MV (1999) Loss of p27Kip1 function results in increased proliferative capacity of oligodendrocyte progenitors but unaltered timing of differentiation. Development 126:4027-4037.

Ciccolini F, Svendsen CN (1998) Fibroblast growth factor 2 (FGF-2) promotes acquisition of epidermal growth factor (EGF) responsiveness in mouse striatal precursor cells: identification of neural precursors responding to EGF and FGF-2. J Neurosci 18:7869-7880.

Cichowski K, Shih TS, Schmit E, Santiago S, Reilly K, McLaughlin ME, Bronson RT, Jacks T (1999) Mouse models of tumor development in neurofibromatosis type 1. Science 286:2172-2176.

Clementi M, Milani S, Mammi I, Boni S, Monciotti C, Tenconi R (1999) Neurofibromatosis type 1 growth charts. Am J Med Genet 87:317-323.

Costa RM, Federov NB, Kogan JH, Murphy GG, Stern J, Ohno M, Kucherlapati R, Jacks T, Silva AJ (2002) Mechanism for the learning deficits in a mouse model of neurofibromatosis type 1. Nature 415:526-530.
Dasgupta B, Dugan LL, Gutmann DH (2003) The neurofibromatosis 1 gene product neurofibromin regulates pituitary adenylate cyclase-activating polypeptide-mediated signaling in astrocytes. J Neurosci 23:8949-8954.

Dasgupta B, Li W, Perry A, Gutmann DH (2005) Glioma formation in neurofibromatosis 1 reflects preferential activation of K-RAS in astrocytes. Cancer Res 65:236-245.

Engstrom C, Demers D, Dooner M, McAuliffe C, Benoit BO, Stencel K, Joly M, Hulspas R, Reilly JL, Savarese T, Recht LD, Ross AH, Quesenberry PJ (2002) A method for clonal analysis of epidermal growth factorresponsive neural progenitors. J Neurosci Methods 117:111-121.

Feng L, Hatten ME, Heintz N (1994) Brain lipid-binding protein (BLBP): a novel signaling system in the developing mammalian CNS. Neuron 12:895-908.

Galli R, Binda E, Orfanelli U, Cipelletti B, Gritti A, De Vitis S, Fiocco R, Foroni C, Dimeco F, Vescovi A (2004) Isolation and characterization of tumorigenic, stem-like neural precursors from human glioblastoma. Cancer Res 64:7011-7021.

Graham V, Khudyakov J, Ellis P, Pevny L (2003) SOX2 functions to maintain neural progenitor identity. Neuron 39:749-765.

Groszer M, Erickson R, Scripture-Adams DD, Lesche R, Trumpp A, Zack JA, Kornblum HI, Liu X, Wu H (2001) Negative regulation of neural stem/ progenitor cell proliferation by the Pten tumor suppressor gene in vivo. Science 294:2186-2189.

Gutmann DH, Aylsworth A, Carey JC, Korf B, Marks J, Pyeritz RE, Rubenstein A, Viskochil D (1997) The diagnostic evaluation and multidisciplinary management of neurofibromatosis 1 and neurofibromatosis 2 . JAMA 278:51-57.

Hartfuss E, Galli R, Heins N, Gotz M (2001) Characterization of CNS precursor subtypes and radial glia. Dev Biol 229:15-30.

Hemmati HD, Nakano I, Lazareff JA, Masterman-Smith M, Geschwind DH, Bronner-Fraser M, Kornblum HI (2003) Cancerous stem cells can arise from pediatric brain tumors. Proc Natl Acad Sci USA 100:15178-15183.

Hope KJ, Jin L, Dick JE (2004) Acute myeloid leukemia originates from a hierarchy of leukemic stem cell classes that differ in self-renewal capacity. Nat Immunol 5:738-743.

Kinoshita T, Yokota T, Arai K, Miyajima A (1995) Regulation of Bcl-2 expression by oncogenic Ras protein in hematopoietic cells. Oncogene 10:2207-2212.

Lakkis MM, Golden JA, O’Shea KS, Epstein JA (1999) Neurofibromin deficiency in mice causes exencephaly and is a modifier for Splotch neural tube defects. Dev Biol 212:80-92.

Largaespada DA, Brannan CI, Jenkins NA, Copeland NG (1996) Nf1 deficiency causes Ras-mediated granulocyte/macrophage colony stimulating factor hypersensitivity and chronic myeloid leukemia. Nat Genet 12:137-143.

Lendahl U, Zimmerman LB, McKay RD (1990) CNS stem cells express a new class of intermediate filament protein. Cell 60:585-595.

Li H, Babiarz J, Woodbury J, Kane-Goldsmith N, Grumet M (2004) Spatiotemporal heterogeneity of CNS radial glial cells and their transition to restricted precursors. Dev Biol 271:225-238.

Listernick R, Charrow J, Greenwald MJ, Mets M (1994) Natural history of optic pathway tumors in children with neurofibromatosis type 1: a longitudinal study. J Pediatr 125:63-66.

Listernick R, Charrow J, Gutmann DH (1999) Intracranial gliomas in neurofibromatosis 1. Am J Med Genet 89:38-44.

Liu Y, Han SS, Wu Y, Tuohy TM, Xue H, Cai J, Back SA, Sherman LS, Fischer I, Rao MS (2004) CD44 expression identifies astrocyte-restricted precursor cells. Dev Biol 276:31-46.

Lu QR, Yuk D, Alberta JA, Zhu Z, Pawlitzky I, Chan J, McMahon AP, Stiles CD, Rowitch DH (2000) Sonic hedgehog-regulated oligodendrocyte lineage genes encoding bHLH proteins in the mammalian central nervous system. Neuron 25:317-329.

Malatesta P, Hartfuss E, Gotz M (2000) Isolation of radial glial cells by fluorescent-activated cell sorting reveals a neuronal lineage. Development 127:5253-5263.

Martin GA, Viskochil D, Bollag G, McCabe PC, Crosier WJ, Haubruck H, Conroy L, Clark R, O'Connell P, Cawthon RM (1990) The GAP-related domain of the neurofibromatosis type 1 gene product interacts with ras p21. Cell 16:843-849.

Molofsky AV, Pardal R, Iwashita T, Park IK, Clarke MF, Morrison SJ (2003) Bmi-1 dependence distinguishes neural stem cell self-renewal from progenitor proliferation. Nature 425:962-967. 
Noctor SC, Flint AC, Weissman TA, Wong WS, Clinton BK, Kriegstein AR (2000) Dividing precursor cells of the embryonic cortical ventricular zone have morphological and molecular characteristics of radial glia. J Neurosci 22:3161-3173.

North KN, Riccardi V, Samango-Sprouse C, Ferner R, Moore B, Legius E, Ratner N, Denckla MB (1997) Cognitive function and academic performance in neurofibromatosis. 1: consensus statement from the NF1 Cognitive Disorders Task Force. Neurology 48:1121-1127.

Nunes MC, Roy NS, Keyoung HM, Goodman RR, McKhann II G, Jiang L, Kang J, Nedergaard M, Goldman SA (2003) Identification and isolation of multipotential neural progenitor cells from the subcortical white matter of the adult human brain. Nat Med 9:439-447.

Sanai N, Tramontin AD, Quinones-Hinojosa A, Barbaro NM, Gupta N, Kunwar S, Lawton MT, McDermott MW, Parsa AT, Manuel-Garcia Verdugo J, Berger MS, Alvarez-Buylla A (2004) Unique astrocyte ribbon in adult human brain contains neural stem cells but lacks chain migration. Nature 427:740-744.

Singh SK, Clarke ID, Terasaki M, Bonn VE, Hawkins C, Squire J, Dirks PB (2003) Identification of a cancer stem cell in human brain tumors. Cancer Res 63:5821-5828.
Tropepe V, Sibilia M, Ciruna BG, Rossant J, Wagner EF, van der Kooy D (1999) Distinct neural stem cells proliferate in response to EGF and FGF in the developing mouse telencephalon. Dev Biol 208:166-188.

Uwanogho D, Rex M, Cartwright EJ, Pearl G, Healy C, Scotting PJ, Sharpe PT (1995) Embryonic expression of the chicken Sox2, Sox3 and Sox11 genes suggests an interactive role in neuronal development. Mech Dev 49:23-36.

Vogel KS, Klesse LJ, Velasco-Miguel S, Meyers K, Rushing EJ, Parada LF (1999) Mouse tumor model for neurofibromatosis type 1. Science 286:2176-2179.

Xu GF, O'Connell P, Viskochil D, Cawthon R, Robertson M, Culver M, Dunn D, Stevens J, Gesteland R, White R (1990) The neurofibromatosis type 1 gene encodes a protein related to GAP. Cell 62:599-608.

Yoon SO, Lois C, Alvirez M, Alvarez-Buylla A, Falck-Pedersen E, Chao MV (1996) Adenovirus-mediated gene delivery into neuronal precursors of the adult mouse brain. Proc Natl Acad Sci USA 93:11974-11979.

Zhou Q, Choi G, Anderson DA (2001) The bHLH transcription factor Olig2 promotes oligodendrocyte differentiation in collaboration with $\mathrm{Nkx} 2.2$. Neuron 31:791-807. 